В. Д. Карлов ${ }^{1}$, О. Л. Кузнєцов ${ }^{1}$, А. М. Артеменко ${ }^{2}$ А. Д. Карлов ${ }^{1}$

${ }^{1}$ Харківський національний університет Повітряних Сил імені Івана Кожедуба, Харків, Україна

${ }^{2}$ Генеральний штаб Збройних Сил України, Київ, Україна

\title{
ЗНИЖЕННЯ ТОЧНОСТІ ВИМІРЮВАННЯ ЧАСТОТИ ПАЧКИ РАДІОІМПУЛЬСІВ ВНАСЛІДОК ВПЛИВУ УМОВ Ї̈̈ ПОШИРЕННЯ І ВІДБИТТЯ
}

\begin{abstract}
У статті оцінюється точність вимірювання частоти пачки для випадку узгодженої обробки без врахування фазових флуктуацій. Наведено результати експерименту по визначенню статистичних характеристик радіолокаційних сигналів, відбитих від місцевих предметів, розташованих за межами дальності прямої видимості, при поширенні радіохвиль в умовах аномальної рефракції над морем. Отримані гістограми розподілу початкової фази відбитого сигналу РЛС апроксимовані кривою, що відповідає нормальному закону розподілу, а нормована кореляційна функція має осцилюючий характер. Оцінювання частоти радіолокаційного сигналу здійснюється за критерієм максимуму натурального логарифма відношення правдоподібності. В явному вигляді отримано достатню статистику за наявністю фазових флуктуацій. Результати вказують на те, що для сучасних РЛС в умовах регулярного вимірювання, на точність оцінювання частоти пачки радіоімпульсів в значно більшому ступені впливають статистичні характеристики флуктуації фаз ніж відношення сигнал-шум.
\end{abstract}

Ключов і слов а : радіолокаційне спостереження, когерентно-імпульсна РЛС, пачка радіоімпульсів, фазові флуктуації, гаусівський шум.

\section{Вступ}

Постановка проблеми. Виконання сучасними аеродинамічними цілями завдань за призначенням на малих та гранично малих висотах 3 огинанням рельєфу місцевості та зростання їхніх маневрених можливостей обумовлює необхідність оцінювання радіолокаторами різних класів похідних дальності до цілі з максимально високою точністю.

Для рішення задачі визначення похідних дальності за часом з необхідною точністю протягом часо-частотної обробки радіолокаційного сигналу, в когерентно-імпульсних РЛС використовується когерентна пачка радіоімпульсів.

Реальні умови поширення та відбиття даного радіолокаційного сигналу здатні суттєво обмежувати його часову когерентність та якість його часочастотної обробки.

Такими умовами можна вважати: вплив атмосферних неоднорідностей [1-3], доплерівський шум цілі [4-6] та відбиття радіохвиль від земної поверхні зі складним рельєфом місцевості або схвильованої поверхні моря [7-9].

Ступінь когерентності пачки визначає тривалість іiї закономірної фазової структури i, як слід, міру роздільної здатності РЛС за частотою та точність вимірювання частоти вказаного радіолокаційного сигналу.

Оцінка можливого зниження точності вимірювання частоти пачки за рахунок фазових флуктуацій iii радіоімпульсів дозволить визначати умови доцільності оптимізації іiі обробки.

Аналіз останніх досліджень і публікацій. Вдосконалення та розвиток сучасних аеродинамічних об'єктів радіолокаційного спостереження обумовлюють підвищення вимог до засобів їх виявлення та супроводження. В сучасних когерентно-імпульсних РЛС, які забезпечують радіолокаційне спостереження складних маневруючих цілей в складній цільовій та завадовій обстановці, реалізовані алгоритми цифрового когерентного накопичення прийнятого пачкового радіосигналу. Тому, має практичну користь оцінювання помилок вимірювання частоти прийнятої пачки в залежності від статистичних характеристик фазових флуктуацій iii paдіоімпульсів.

Радіолокаційному спостереженню цілей та вимірюванню їх координат й параметрів руху в складних умовах присвячена значна кількість робіт.

Флуктуації фази, що виникають внаслідок впливу атмосферних неоднорідностей та особливості застосування радіотехнічних систем в цих умовах описані в роботах $[1,7,10,12]$. Окрім цього, фазові викривлення прийнятого сигналу, які обумовлені складною формою цілі та ï здатністю до виконання раптового маневру, викликають блукання ії радіолокаційного центру та, як слід, появу швидкісних шумів цілі $[1,4,5,13,14]$.

У випадку багатотрасового поширення радіолокаційного сигналу при радіолокаційному спостереженні цілей, що рухаються під малими кутами місця, також з'являються його додаткові фазові викривлення, що розглядаються у [4, 7, 8, 15-19].

$\mathrm{У}[20]$ наведена методика розрахунку помилки вимірювання частоти пачки, що виникає внаслідок впливу фазових флуктуацій ії радіоімпульсів.

Як показано в роботі [21], можливі значення помилок вимірювання часо-частотних параметрів радіолокаційного сигналу, які виникають внаслідок його фазових спотворень здатні перевищувати допустимі значення РЛС різних діапазонів довжин хвиль. Припущення щодо статистичних характеристик відбитих сигналів підтверджені результатами експериментального дослідження, які висвітлені в [22].

Метою статті $\epsilon$ чисельний аналіз впливу статистичних характеристик фазових флуктуацій радіоімпульсів прийнятої пачки зі знакозмінною кореляційною функцією на зниження точності вимірювання iї частоти. 


\section{Основний матеріал}

Прийнята реалізація представляс собою суму відбитої від цілі пачки радіоімпульсів та внутрішнього шуму приймального пристрою

$$
y(t, \Omega)=x(t, \Omega)+n(t),
$$

де $y(t, \Omega)$ - реалізація прийнятого коливання; $x(t, \Omega)$ - реалізація корисного сигналу; $n(t)$ - реалізація внутрішнього гаусівського шуму; $\Omega$ - циклічний зсув частоти прийнятої пачки радіоімпульсів.

Корисним сигналом $\epsilon$ когерентна пачка радіоімпульсів з випадковою амплітудою і початковою фазою, комплексна амплітуда якої описується як

$$
\dot{X}(t, \Omega)=b \sum_{i=1}^{n} \dot{X}_{i}(t, \Omega) \exp [j(\beta)],
$$

де $\dot{X}_{i}(t, \Omega)$ - комплексна амплітуда $i$-го радіоімпульсу; $b$ - випадкова амплітуда радіосигналу, яка розподілена за законом Релея; $\beta$ - випадкова початкова фаза радіосигналу, яка розподілена за рівномірним законом; $i$ - номер радіоімпульсу, який відлічується від початку пачки; $n$ - кількість радіоімпульсів в пачці.

Згідно [1] визначено, що оцінювання зсуву частоти пачки радіоімпульсів може бути здійснено шляхом знаходження аргументу максимуму натурального логарифму відношення правдоподібності

$$
\widehat{\Omega}=\arg \max \ln \ell(\Omega) .
$$

де $\ell(\Omega)$ - відношення правдоподібності, як функція вимірюваного параметра.

В роботі [1] визначено, що відношення правдоподібності для когерентного сигналу 3 рівномірно розподіленою випадковою фазою й випадковою амплітудою, розподіленою за законом Релея, як результат статистичного усереднення за випадковими параметрами $b$ i $\beta$ має вигляд

$$
\ell(\Omega)=\frac{1}{1+q^{2} / 2} \exp \frac{q^{2} / 2}{2\left(1+q^{2} / 2\right)}\left|Z_{H}(\Omega)\right|^{2},
$$

де $q^{2}$ - відношення сигнал-шум за потужністю; $\left|Z_{H}(\Omega)\right|^{2}$ - квадрат модулю нормованого вагового інтеграла як функція вимірюваного параметра.

В умовах регулярного вимірювання $\left(q^{2}>>1\right)$ справедливою $\epsilon$ рівність

$$
\left|Z_{H}(\Omega)\right|=\left|Z_{H}\left(\vec{\Phi}_{c}, \vec{\Phi}_{o}\right)\right| \approx q \rho\left(\vec{\Phi}_{c} \vec{\Phi}_{o}\right)=q \rho(\Omega),
$$

де $\vec{\Phi}_{c}=\left\|\Phi_{c i}\right\|^{T}(i=1,2, \ldots, n)$ - вектор спостережуваних значень початкових фаз радіоімпульсів пачки; $\vec{\Phi}_{o}=\left\|\Phi_{o i}\right\|^{T}$ - вектор очікуваних значень початкових фаз радіоімпульсів пачки; $\rho\left(\vec{\Phi}_{c}, \vec{\Phi}_{o}\right)=$ $=\rho(\Omega)-$ нормована функція розузгодження за початковою фазою спостережуваного та очікуваного радіосигналу.
3 урахуванням (5) відношення правдоподібності (4) при $q^{2}>1$ приймає вигляд

$$
\ell(\Omega) \approx 2 / q^{2} \exp q^{2} \rho^{2}(\Omega) / 2 .
$$

Як показано в [20], у випадку когерентної пачки 3 постійним періодом слідування радіоімпульсів квадрат нормованої функції розузгодження за частотою описується виразом

$$
\begin{gathered}
\rho^{2}(\Omega)=1-\frac{1}{2} \sum_{i=1}^{n} \sum_{j=1}^{n} \xi_{i} \xi_{j}\left(\Phi_{i}-\Phi_{j}\right)^{2}- \\
-\frac{1}{2} T^{2} \Omega^{2} \sum_{i=1}^{n} \sum_{j=1}^{n} \xi_{i} \xi_{j}(i-j)^{2}+ \\
+T \Omega \sum_{i=1}^{n} \sum_{j=1}^{n} \xi_{i} \xi_{j}(i-j)\left(\Phi_{i}-\Phi_{j}\right),
\end{gathered}
$$

де $\Omega=\omega-\omega_{0}$ - розузгодження між очікуваною $\omega$ й спостережуваною $\omega_{0}$ циклічними частотами пачки імпульсів; $i, j$ - номери імпульсів, які відлічуються від початку пачки; $\Phi_{i}, \Phi_{j}$ - спостережувані значення початкової фази $i$-го і ј-го радіоімпульсів відповідно; $\xi_{i}=\frac{Z_{i}}{Z_{\Sigma}} ; Z_{i}=\frac{1}{2}\left|\int_{-\infty}^{\infty} \dot{Y}_{i}(t) \dot{X}_{i}^{*}(t) d t\right|$ - модуль сигнальної частини комплексного кореляційного інтеграла для $i$-го радіоімпульсу; $\dot{\mathrm{Y}}_{i}(t)$ - комплексна обвідна прийнятого $i$-го радіоімпульсу; $\dot{\mathrm{X}}_{i}^{*}(t)$ комплексно спряжена обвідна опорної напруги при обробці і-го радіоімпульсу; $\mathrm{Z}_{\Sigma}=\sum_{i=1}^{n} \mathrm{Z}_{i} ; \quad T$ - період слідування радіоімпульсів пачки.

Для симетричного амплітудного розподілу радіоімпульсів в пачці $\xi_{i}=\xi_{n+1-i}$, підставляючи вираз (7) у вираз (6), логарифмуючи й залишаючи тільки залежні від вимірюваних параметрів доданки, одержуємо вираз для достатньої статистики

$$
\begin{gathered}
S(\Omega)=-\frac{q^{2}}{2}\left\{\frac{T^{2}}{2} \Omega^{2} \sum_{i=1}^{n} \sum_{j=1}^{n} \xi_{i} \xi_{j}(i-j)^{2}-\right. \\
\left.-T \Omega \sum_{i=1}^{n} \sum_{j=1}^{n} \xi_{i} \xi_{k}(i-j)\left(\Phi_{i}-\Phi_{j}\right)\right\} .
\end{gathered}
$$

Дисперсія помилки оцінювання частоти пачки радіоімпульсів отримується [1] за виразом

$$
\frac{1}{\sigma_{\Omega}^{2}}=-\frac{d^{2} \ln \ell(\Omega)}{d \Omega^{2}}=-\frac{d^{2} S(\Omega)}{d \Omega^{2}} \text { при } \Omega=\widehat{\Omega},
$$

де $\ln \ell(\Omega)$ - натуральний логарифм відношення правдоподібності (6) або його достатньої статистики (8); $\widehat{\Omega}$ - оцінка частоти пачки радіоімпульсів.

Після дворазового диференціювання по вимірюваному параметру достатньої статистики (8) одержуються дисперсія помилки оцінювання частоти 


$$
\frac{1}{\sigma_{\Omega}^{2}}=\frac{q^{2} T^{2}}{2} \sum_{j=1}^{m} \xi_{j}(2 j-1)^{2},
$$

де $R_{j}$ - різниця початкових фаз $j$-ої симетричної пари радіоімпульсів; $\mathrm{m}$ - число пар радіоімпульсів, симетричних відносно центру пачки. Якщо пачка радіоімпульсів має прямокутну, обвідну $\left(\xi_{i}=1 / n\right)$, вираз (10) можна перетворити до вигляду

$$
\frac{1}{\sigma_{\Omega}^{2}}=\frac{q^{2}\left(4 m^{2}-1\right)}{12} T^{2} .
$$

Дисперсія випадкової помилки виміру частоти, обумовленої флуктуаціями початкових фаз імпульссів пачки може бути представлена виразом [20]

$$
\sigma_{\Omega \phi л}^{2}=\frac{9}{m^{2}\left(4 m^{2}-1\right)^{2} T^{2}}\left\langle\left[\sum_{j=1}^{m}(2 j-1) \Delta R_{j}\right]^{2}\right\rangle .
$$

де $\langle>$-операція статистичного усереднення.

Дисперсія загальної помилки вимірювання частоти пачки радіоімпульсів визначається сумою дисперсії $\sigma_{\Omega}^{2}$ помилки (11) обумовленої впливом внутрішніх шумів приймального пристрою й дисперсії $\sigma_{\Omega \phi л}^{2}$ помилки (12), викликаної фазовими флуктуаціями радіоімпульсів пачки

$$
\sigma_{\Sigma}^{2}=\sigma_{\Omega}^{2}+\sigma_{\Omega \phi л}^{2} .
$$

Вважається, що фазові флуктуації радіоімпульсів прийнятої пачки розподілені за нормальним законом, а кореляція фазових флуктуацій радіоімпульсів пачки убуває від імпульсу до імпульсу за знакозмінним законом. Вказані припущення підтверджуються результатами експерименту, наведеними у [22]. При його проведенні, у якості радіолокаційного вимірювача було використано розташовану на узбережжі Азовського моря РЛС 35Д6Д. В ході експерименту вказана когерентно-імпульсна РЛС використовувалася у 4-му режимі огляду простору при рідкому запуску (частота повторення зондуючих сигналів складала 690...820 Гц).

Для статистичного аналізу було використано 4984 значення напруги у квадратурних каналах РЛС. На рис. 1 наведено гістограма розподілу початкової фази відбитого сигналу. Плавна крива, яка апроксимує цей розподіл та позначена цифрою 1 відповідає нормальному закону.

На рис. 2 наведено результати кореляційного аналізу даних експерименту. Пунктирною лінією позначена нормована кореляційна функція $R_{\varphi}(\tau)$ фази відбитого сигналу. Як можна побачити функція $R_{\varphi}(\tau)$ має осцилюючий характер.

Таким чином, в умовах аномальної рефракції при поширенні електромагнітних хвиль над морем амплітуда та початкова фаза радіолокаційних сигналів розподілені за нормальним законом. При цьому, нормованая кореляційна функція фази відбитого сигналу мае осцилюючий характер.

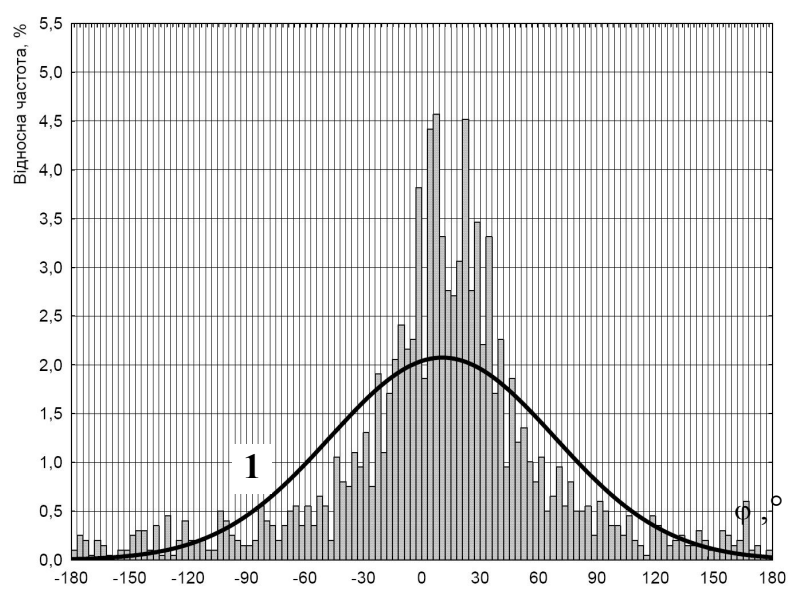

Рис. 1. Гістограма і графік функції розподілу фази

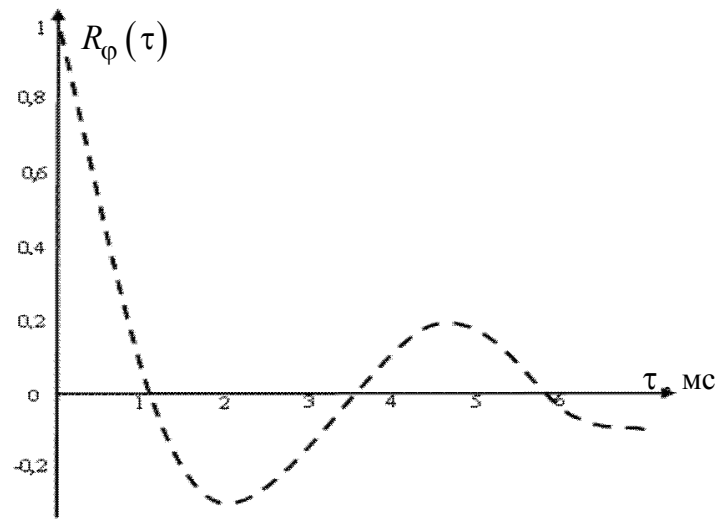

Рис. 2. Нормована кореляційна функція фази відбитого сигналу

Відповідно до результатів експерименту, з урахуванням частоти слідування радіоімпульсів пачки когерентно-імпульсної РЛС, можна вважати, що кореляція відбитого пачкового радіосигналу від імпульсу до імпульсу убуває за знакозмінним законом.

Реалізація статистичного усереднення (12) дозволяє отримати вираз дисперсії загальної помилки вимірювання частоти пачки радіоімпульсів при знакозмінній кореляційній функції фазових флуктуацій

$$
\begin{gathered}
\sigma_{\Sigma}^{2}=\frac{12}{q^{2} T^{2}\left(4 m^{2}-1\right)}+\frac{18 \sigma_{\varphi}^{2}}{m^{2} T^{2}\left(4 m^{2}-1\right)^{2}} \times \\
\times\left[\sum_{k=1}\left((2 k-1)^{2}\left(1-(-a)^{(2 k-1)}\right)\right)+2 \times\right. \\
\left.\times \sum_{k=1}^{m-1} \sum_{i=1}^{m-k}(-a)^{i}(2 k-1)(2 k+2 i-1)\left(1-(-a)^{(2 k-1)}\right)\right],
\end{gathered}
$$

де $\sigma_{\varphi}^{2}$ - дисперсія фазових флуктуацій; $a$ - коефіцієнт кореляції фазових флуктуацій сусідніх радіоімпульсів пачки.

Нижче наданні графіки залежності $\left(\sigma_{\Sigma} T\right)^{2}$ від відношення сигнал-шум по потужності $q^{2}$ при а=0,99 (рис. 3, а) та від коефіцієнта кореляції фазових флуктуацій (рис. 3, б) при $q^{2}=1000$. Графіки отримані для значень дисперсії фазових флуктуацій $\sigma_{\varphi}^{2}=0,01 ; 0,1 ; 1 ; 10$ pad $^{2}$. 


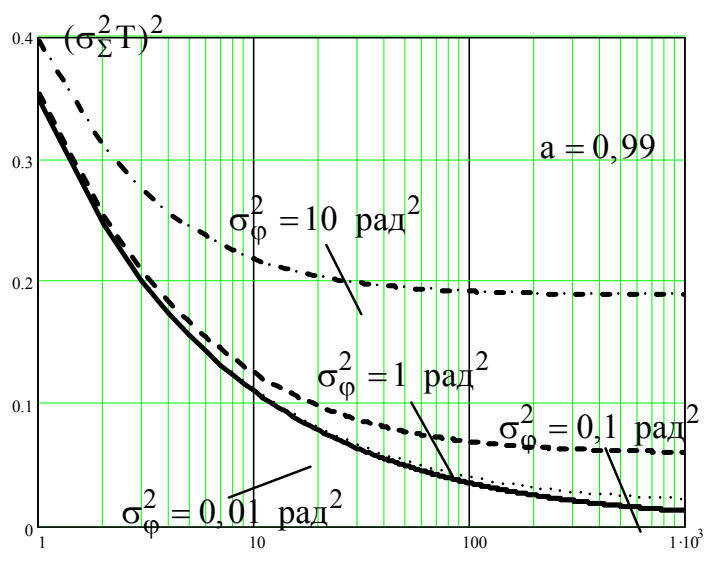

$q^{2}$

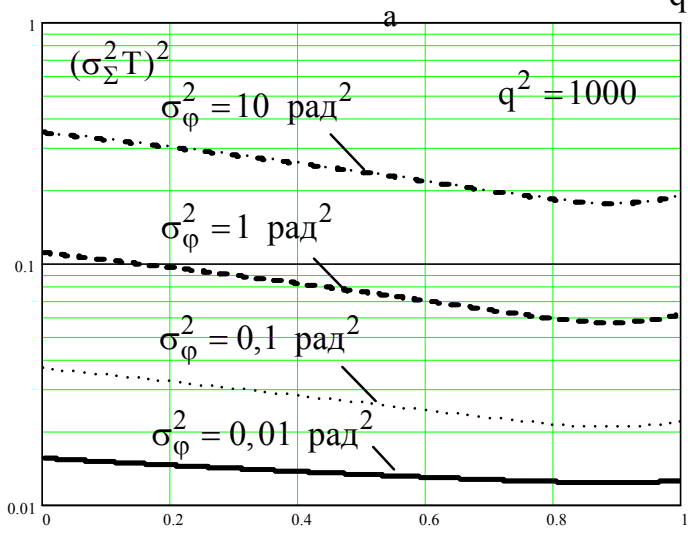

6

Рис. 3. Дисперсія помилки вимірювання частоти пачки радіоімпульсів при відсутності врахування фазових флуктуацій

Результати наведені на рис. 3, а вказують на те, що в умовах регулярного вимірювання (при $\left.q^{2}>>1\right)$, точність вимірювання частоти пачки радіоімпульсів переважно залежить від статистичних характеристик фазових флуктуацій ніж від величини відношення сигнал-шум. Збільшення дисперсії фазових флуктуацій на порядок в області малих значень $\left(\sigma_{\varphi}^{2}=0,01 \ldots 0,1 p a \partial^{2}\right)$ майже не впливає на зміну величини дисперсії помилки вимірювання частоти пачки радіоімпульсів. Збільшення даної дисперсії на порядок в області суттєвих значень $\left(\sigma_{\varphi}^{2}=1 \ldots 10\right.$ рад $\left.{ }^{2}\right)$, які можуть мати місце в практичних випадках, призводить до зростання дисперсії помилки вимірювання частоти пачки радіоімпульсів на порядок і більше. Дані результати отримані для знакозмінної кореляційної функції фазових флуктуацій, при зменшенні коефіцієнта міжімпульсної кореляції лише на 1\% ( $a=0,99)$.

Графіки на рис. 3,б вказують на те, що при збільшенні дисперсії фазових флуктуацій $\left(\sigma_{\varphi}^{2}=0,01 \ldots 10\right.$ pad $\left.^{2}\right)$, збільшується вплив коефіцієнту їх міжімпульсної кореляції на помилку вимірювання частоти пачки радіоімпульсів. Причому найбільш суттєво цей ефект має місце при великих величинах дисперсії фазових флуктуацій $\left(\sigma_{\varphi}^{2}=1 \ldots 10\right.$ рад $\left.{ }^{2}\right)$, що дійсно може мати місце в реальних умовах виконання РЛС завдань за призначенням.

\section{Висновки}

Експериментальні дані вказують, що при роботі когерентно-імпульсної РЛС в реальних умовах, має місце виникнення флуктуацій початкових фаз радіоімпульсів прийнятої пачки 3 нормальним законом розподілу та знакозмінною кореляційною функцією. Дані флуктуації в значному ступені здатні знизити якість часо-частотної обробки радіолокаційного сигналу, що вказує на необхідність ії оптимізації.

\section{СПИСОК ЛІТЕРАТУРИ}

1. Довідник учасника АТО: озброєння і військова техніка Збройних Сил Російської Федерації / А.М. Алімпієв, Г.В. Пєвцов, Д.А. Гриб та ін.; за заг. ред. А.М. Алімпієва. - Х.: Оригінал, 2015. - 732 с.

2. Вопросы статистической теории антенн / Я.С. Шифрін. - М: Сов. радио, 1970. -383 с.

3. Карлов В.Д. Влияние среды распространения радиоволн на приморском направлении при измерении угловых координат радиолокационных целей / В.Д. Карлов, Н.Н. Петрушенко, В.В. Челпанов, К.П. Квиткин // Збірник наукових праць Харківського університету Повітряних Сил. - 2010. - № 3 (25). - С. 51-53.

4. Справочник по радиолокации / Под ред. М. Сколника. - М: Сов. радио, 1976, Т 1. - 456 с.

5. Статистическая теория радиолокации протяженных целей / Р. В. Островитянов. - М: Радио и связь, 1982. -232 с.

6. Обнаружение аэродинамических целей в условиях шумовых и пассивных помех с широким доплеровским спектром / В.Д. Карлов, И.Г. Леонов, А.Е. Присяжный, О.Я. Луковский // Системи обробки інформації. - 2006. - № 9(58). C. 34-36.

7. Влияние тропосферы и подстилающей поверхности на работу РЛС / Н.П. Красюк - М: Радио и связь, 1988. - 223 с.

8. Котов А.Ф. Влияние отражений от подстилающей поверхности на процесс локации объектов // Теория и практика систем синхронизации / Московский институт радиотехники электроники и автоматики. - 1992. - С.4-8.

9. Карлов В.Д. Влияние неоднородностей рельефа позиции радиолокационной станции на эффективность подавления внешней помехи при локации надводных целей / В.Д. Карлов, Н.Н. Минервин, Н.Н. Петрушенко, Е.В. Лукашук // Системи управління навігації та зв’язку. - 2008. - № 4 (8). - С. 34-36.

10. Петрушенко М. М. Особливості застосування радіотехнічних систем Повітряних Сил в нестабільних гідрометеорологічних умовах / М. М. Петрушенко // Системи управління навігації та зв’язку. - 2009. - № 2 (10). - С. 54-57.

11. Карлов В.Д. Влияние флуктуаций фронта помеховой волны на эффективность её подавления корреляционным компенсатором в радиотехнических системах приморского базирования / В.Д. Карлов, Н.Н. Минервин, Н.Н. Петрушенко, Е.В. Лукашук, О.Я. Луковский // Системи обробки інформації. - 2008. - № 7 (74). - С. 87-93.

12. Карлов В.Д. До питання про вимірювання дальності маловисотної цілі при їі радіолокації в межах тропосферного хвилеводу над морем / В.Д. Карлов, Д.Б. Кучер, О.В. Струцинський, О.В. Лукашук // Наука і техніка Повітряних Сил Збройних Сил України. - 2016. - № 3 (24). - С. 98-101. 
13. Карлов В.Д. К вопросу о измерении доплеровской частоты сигнала отраженного от цели лоцируемой за пределами радиогоризонта над морем / В.Д. Карлов, А.П. Кондратенко, А.К. Шейгас, Ю.Б. Ситник // Наука і техніка Повітряних Сил Збройних Сил України. - 2014. - № 1 (14). - С. 115-117.

14. Карлов В.Д. Особливості вимірювання радіальної складової швидкості цілі, лоцюємої під малими кутами місця над морем / В.Д. Карлов, М.М. Петрушенко, Г.В. Пєвцов, А.І. Нос // Новітні технології-для захисту повітряного простору: зб. тез доповідей Восьмої наукової конференції ХУПС. 18-19 квітня 2012 р. - Харків, 2012. - С. 295.

15. Svyrydov, A., Kuchuk, H., Tsiapa, O. (2018), "Improving efficienty of image recognition process: Approach and case study", Proceedings of 2018 IEEE 9th International Conference on Dependable Systems, Services and Technologies, DESSERT 2018, pp. 593-597, available at: http://dx.doi.org/10.1109/DESSERT.2018.8409201

16. Kuchuk G., Kovalenko A., Komari I.E., Svyrydov A., Kharchenko V.. Improving big data centers energy efficiency: Traffic based model and method. Studies in Systems, Decision and Control, vol 171. Kharchenko, V., Kondratenko, Y., Kacprzyk, J. (Eds.). Springer Nature Switzerland AG, 2019. Pp. 161-183. DOI: http://doi.org/10.1007/978-3-030-00253-4 \&

17. Коваленко А. А., Кучук Г. А. Методи синтезу інформаційної та технічної структур системи управління об'єктом критичного застосування. Сучасні інформаційні системи. 2018. Т. 2, № 1. С. 22-27. DOI: https://doi.org/10.20998/2522-9052.2018.1.04

18. Коваленко А. А. Подходы к синтезу информационной структуры системы управления объектом критического применения / А.А. Коваленко // Системи обробки інформації. - 2014. - № 1(117). - С. 180-184.

19. Свиридов А. С., Коваленко А. А., Кучук Г. А. Метод перерозподілу пропускної здатності критичної ділянки мережі на основі удосконалення ON/OFF-моделі трафіку. Сучасні інформачійні системи. 2018. Т. 2, № 2. C. 139-144. DOI: https://doi.org/10.20998/2522-9052.2018.2.24

20. Минервин Н.Н. Ошибки измерения радиальной скорости и радиального ускорения цели, обусловленные неучетом флюктуаций фаз импульсов пачки / Н.Н. Минервин, А.Л. Кузнецов // Авіаційно-космічна техніка і технологія - 2001. - № 22. - C. 288-294.

21. Мінервін М.М. Ограничение точности измерения радиальной скорости цели за счет условий распространения, отражения и обработки радиолокационного сигнала / М.М. Мінервін, О.Л. Кузнєцов, В.А. Таршин // Збірник наукових праць Харківського університету Повітряних Сил. - 2006. - № 3 (9). - С. 116-118.

22. Карлов В.Д. Статистичні характеристики радіолокаційних сигналів відбитих від місцевих предметів в умовах аномальної рефракції. / В.Д. Карлов, А.О. Родюков, І.М. Пічугін // Наука і техніка ПС ЗС України. - 2015. - Вип. 4 (21). - С. 71-74.

Рецензент: д-р техн. наук. проф. Л. Ф. Купченко, Харківський національний університет Повітряних Сил ім. І. Кожедуба, Харків. Received (Надійшла) 13.05.2019

Accepted for publication (Прийнята до друку) 31.07.2019

\section{Снижение точности измерения частоты пачки радиоимпульсов вследствие влияния условий ее распространения и отражения \\ В. Д. Карлов, А. Л. Кузнецов, А. Н. Артеменко, А. Д. Карлов}

В статье оценивается точность измерения частоты пачки для случая согласованной обработки без учета фазовых флуктуаций. Приведены результаты эксперимента по определению статистических характеристик радиолокационных сигналов, отраженных от местных предметов, расположенных за пределами дальности прямой видимости, при распространении радиоволн в условиях аномальной рефракции над морем. Полученные гистограммы распределения начальной фазы отраженного сигнала РЛС аппроксимированы кривой, соответствующей нормальному закону распределения, а нормированная корреляционная функция имеет осциллирующий характер. Оценивание частоты радиолокационного сигнала осуществляется по критерию максимума натурального логарифма отношения правдоподобия. В явном виде получена достаточная статистика при налички фазовых флуктуаций. Результаты свидетельствуют о том, что для современных РЛС в условиях регулярного измерения, на точность оценивания частоты пачки радиоимпульсов в значительно большей степени влияют статистические характеристики флуктуаций фаз чем отношение сигнал-шум.

Ключевые слова: радиолокационное наблюдение, когерентно-импульсная РЛС, пачка радиоимпульсов, фазовые флуктуации, гауссовский шум.

Reducing the accuracy of measuring frequency of the radio pulse burst due to the influence of the conditions of its propogation and reflection

V. Karlov, O. Kuznietsov, A. Artemenko, A. Karlov

The accuracy of the measurement of the burst frequency for case of coordinated processing without taking into account the phase fluctuations is evaluated in this article. Results are demonstrated of experiment on determination of statistical characteristics of radar's signals, reflected from local objects, located outside distance of direct visibility, at propagation of radio waves in the conditions of anomalous refraction above a sea. The obtained histograms of the distribution of the initial phase of the reflected signal of the radar are fitted with a curve corresponding to the normal distribution, and the normalized correlation function has an oscillating character. The signals at the input of the radar's receiver is an additive mixture of signals reflected from the targets, and uncorrelated Gaussian noise, that is the assumption of investigating. It is assumed, that the phase fluctuations of the received radio pulses bursts are distributed according to normal probability laws with zero mean, and correlations of phase fluctuations decrease with alternating, sign-variable laws by increasing interval between radio pulses within the bursts. The frequency of radio signal is estimated by the maximum criterion of the natural logarithm of the likelihood ratio. An explicit expression is obtained a sufficient statistics during the presence of phase fluctuations. The results show that under condition of a regular measurement, the accuracy of measuring the frequency of a burst of radio pulses is much more affected by the statistical characteristics of phase fluctuations than the signal-to-noise ratio in modern radars.

Keywords : radar surveillance, coherent pulse radar, burst of radio pulses, phase fluctuations, Gaussian noise. 